\section{Original Research}

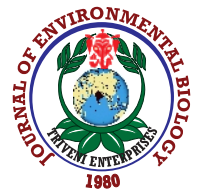

DOI : http://doi.org/10.22438/jeb/415(SI)/MS_19
Journal Home page : www.jeb.co.in $\star$ E-mail : editor@jeb.co.in Journal of Environmental Biology

p-ISSN: 0254-8704

e-ISSN: 2394-0379 CODEN: JEBIDP
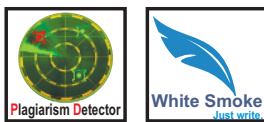

\title{
Embryonic development of marine ornamental shrimp, Lysmata amboinensis (De Man, 1888)
}

\author{
W.N.A. Omar ${ }^{1,2}$, A. Arshad ${ }^{1,2}$, S.M.N. Amin ${ }^{1,3}$ and A. Christianus ${ }^{2}$ \\ ${ }^{1}$ International Institute of Aquaculture and Aquatic Sciences (I-AQUAS), Universiti Putra Malaysia, 71050 Port Dickson, Negeri Sembilan, Malaysia \\ ${ }^{2}$ Department of Aquaculture, Faculty of Agriculture, Universiti Putra Malaysia, Serdang, Selangor 43400, Malaysia \\ ${ }^{3}$ FAO World Fisheries University, Pukyong National University, Nam - gu, Busan 48547, South Korea \\ *Corresponding Author Email : azizarshad@upm.edu.my
}

\section{Abstract}

Aim: In this study, reproductive cycle, particularly embryonic development stages of Lysmata amboinensis are discussed.

Methodology : Four pairs of broodstock were reared in tanks under following conditions : $28^{\circ} \mathrm{C} \pm 1{ }^{\circ} \mathrm{C}, 30 \mathrm{ppt}$ salinity and $12 \mathrm{~L}$ : $12 \mathrm{D}$ photoperiod. The observations on the spawning activities and reproductive cycle were recorded. Digital images of eggs development were taken, described and illustrated. In addition, eggs of each stage were kept in $4 \%$ formalin for histological procedures.

Results : Cleaner shrimp went through seven phases of embryonic development viz. unfertile phase, cleavage, blastula, gastrula, prenauplius stage, post-nauplius stage and complete embryo phase within approximate 13 days of incubation period. The present investigation aided by histological procedure showed that primordial cells (PCs) were detected early in the examined embryos and formed germ disc as gastrula stage begun. Gastrula stage was a superior stage of embryonic development where organ enlarged to form early structure of the organism.

Interpretation : The understanding of the embryology process would be helpful to enhance the breeding trials of this particular shrimp.

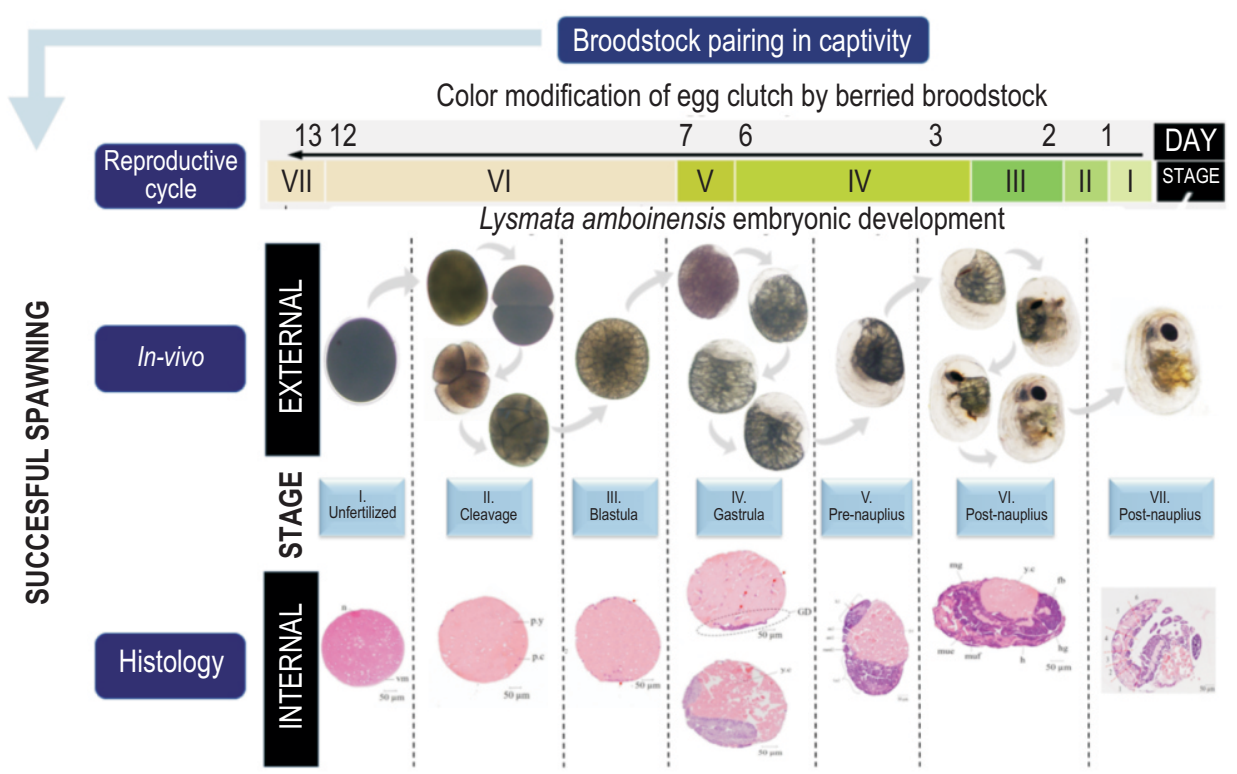

Key words : Embryonic development, Lysmata amboinensis, Reproductive cycle

How to cite : Omar, W.N.A., A. Arshad, S.M.N. Amin and A. Christianus: Embryonic development of marine ornamental shrimp, Lysmata amboinensis (De Man, 1888). J. Environ. Biol., 41, 1264-1274 (2020). 


\section{Introduction}

Lysmata amboinensis generally known as "cleaner shrimp" is among the most extremely traded invertebrates in marine aquarium industry due to its bright coloration and endurance (Calado et al., 2003; Wabnitz et al., 2003; Rhyne et al., 2017). Earlier, several attempts have been made to improve technologies for extensive culture of few decapod species, including $L$. amboinensis, but with meagre achievement (Lin et al., 2002; Calado, 2008; Calado et al., 2008; Calado et al., 2017). One of the main reasons is insufficient biological data on this species. Biological information such as reproduction, embryonic development, and larval development are essential for the development of marine ornamental aquaculture breeding technology. In decapod crustaceans, embryonic development is associated with changes in embryo color, size and morphology during reproductive cycle (Sarker et al., 2012; Romero-Carvajal et al., 2018). Crustacean embryonic development offers an exclusive, valuable, and perceptive instrument for both developmental processes and physiological regulatory mechanisms (Dinakaran et al., 2013). With present available information, limited studies has been carried out on the early life development of $L$. amboinensis. Therefore, this study was carried out to examine the details embryonic development of this species under laboratory conditions.

\section{Materials and Methods}

Four adult pairs of $L$. amboinensis with similar sizes were bought from local marine ornamental shop. Each pair was placed in broodstock aquarium $(0.40 \mathrm{~m} \times 0.21 \mathrm{~m} \times 0.29 \mathrm{~m})$ using under gravel filter system with constant aeration at $28^{\circ} \mathrm{C}, 30 \mathrm{ppt}$ salinity and 12L: $12 \mathrm{D}$ photoperiod. Small pebbles were used as substrate and refuge from dead corals was also provided. Shrimps were fed daily with frozen squid, polychaetes and mussel (ad libitum). Each aquarium was daily observed for the presence of exuviate or eggs on shrimp pleopods. Reproductive cycle and eggs development process was daily observed in details.

Eggs were sampled in random positions in the brood pouch by gently removing a clutch of eggs and examined in-vivo using light microscope (10x,20x and 40x magnification) to describe their morphologies. Digital image of the eggs was taken, described and illustrated. Daily color changes of the eggs clutch during incubation period were also noted. Progressive changes in the embryonic development and increase in the eggs size were recorded to document different developmental stages. Diameters of 30 eggs were randomly selected at each stage to calculate the egg volume by the formula : $E V=1 / 6\left(\pi d^{1} \times \pi d^{2}\right)$ for prolate spheroids, where, $d^{1}$ is the least diameter and $d^{2}$ is the greatest diameter (Zhang et al., 1998). One-way ANOVA test using the software IBM SPSS (predictive analytics software) was applied to detect possible significant differences of egg volume development.
Eggs of each stage were also saved in $4 \%$ formalin and dehydrated by series of gradient prepared alcohol, embedded in paraffin. The blocks were sectioned serially at $4-6 \mathrm{~m}$ using a Leitz manual rotary microtome. Staining was performed with Harris's haematoxylin and eosin method. The slides were observed under a microscope Olympus BX43 microscope equipped with a camera Olympus DP22 using Olympus cellSens Standard 1.13 software.

\section{Results and Discussion}

Reproductive cycle and behaviour : During 60 days of experimental period, the four mating pairs underwent two mating events with $100 \%$ survival. After a successful copulation process, the shrimp maintained the eggs clutched to the brood pouch until hatching. The berried broodstock molted between 12 to $24 \mathrm{hrs}$ after larval hatching process (Fig. 1). Ecdysis or premating moult is commonly seen in many crustaceans and this process was also observed in L. amboinensis. Mating and spawning occurred within $12 \mathrm{hr}$ after one of the hermaphrodites bloodstock ecdysis. In the present study, spawning occurred after moulting either with or without successful copulation. However, unsuccessful copulation produced infertile eggs and the egg were discarded. Isolated individuals of $L$. amboinensis were incapable to spawn fertile eggs (Fiedler, 1998), indicating that this species do not keep exogenous sperm or self-fertilized (Leal et al., 2016). The berried broodstock cleaned up their broods by eating their own infertile eggs using the chelipeds. The infertile eggs produced by the shrimp disappeared within four days as suggested by Fiedler (1998) and is in agreement with this study.

Depending on the species post-molting behavior, the timing to successful mating and production of new egg batch can be misled as the shrimp separated from the partners for hatching process before re-establishing as a breeding pair (Calado, 2008). Berried broodstock of $L$. amboinensis were observed to incubate their fertile eggs on abdominal pleopod until hatched. They also provided maternal care by frequently fanning their eggs using pleopod and cleaned them using small pincer of first anterior pereipod throughout the incubation pareopods. Similar to those reported by Bauer (2004) and Tziouveli and Smith (2009), L. amboinensis kept their incubated eggs healthy by grooming the egg clutch with their advanced specialized appendages until hatching. According to Thiel (2000), this kind of parental care offer a large amount of yolk to each individual eggs. The yolk reserve sustained egg and larval development during the embryonic phase as a result, higher survival rate of larvae produced (Brillon etal., 2005).

\section{Embryonic development of living egg}

Egg incubation period: Under laboratory conditions $\left(28^{\circ} \mathrm{C}, 30\right.$ ppt), it was found that egg of $L$. amboinensis completed their development in 13 days. Many studies have proven that the incubation period is species-dependent (Bauer, 2004). 


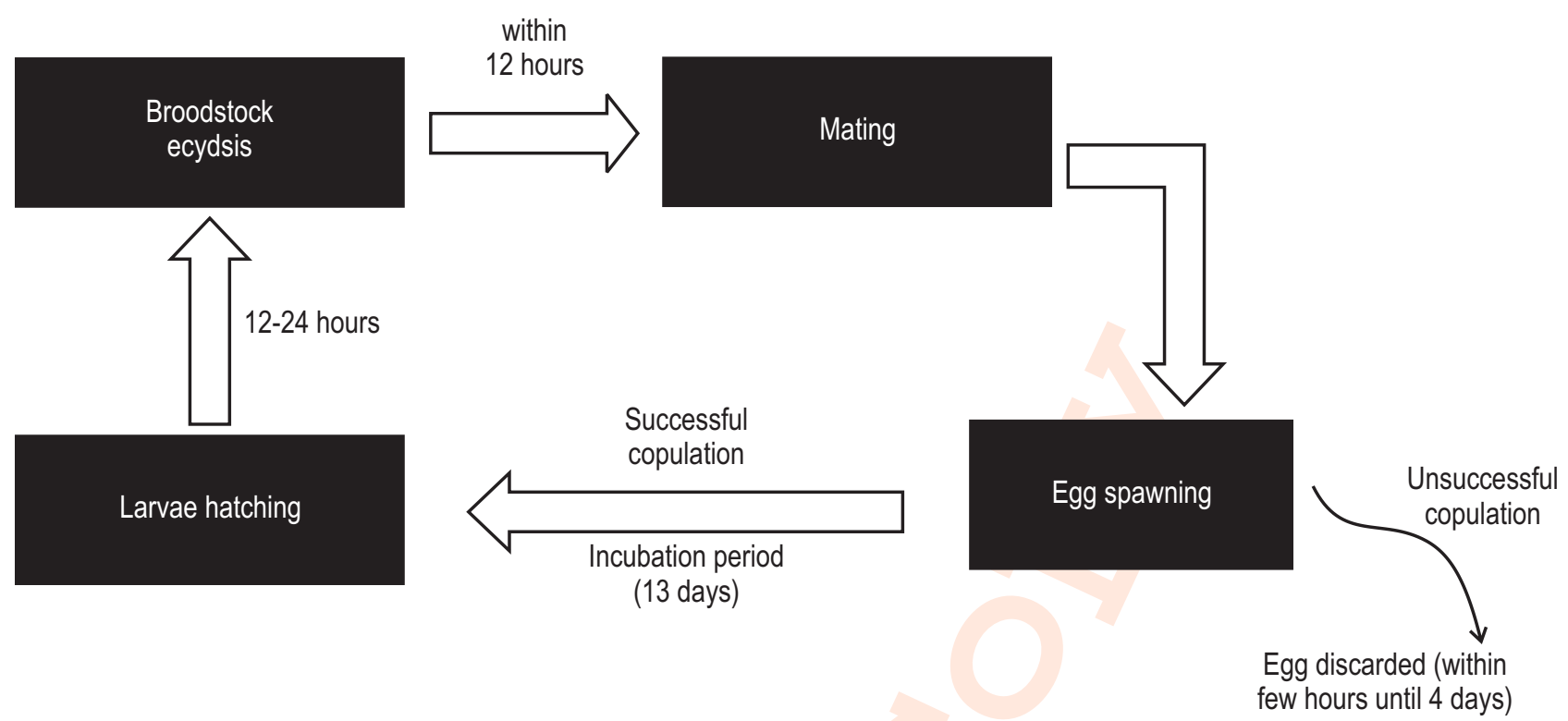

Fig. 1 : Reproductive cycle of $L$. amboinensis under laboratory conditions. The scheme shows the relationship among ecdysis, spawning, mating and larvae hatching, based on the observation of four mating pairs during 60 days.

Depending on several factors particularly temperature, other coral shrimp species may have a extended period of embryonic development, as in Erimacrus isenbeckii which require over 12 months to complete its egg development at $5.7^{\circ} \mathrm{C}$ (Nagao et al., 1999). Generally, long duration of embryonic development occur in species that live in cold and deep water. Besides, temperature also plays a vital role in egg incubation as decrease in water temperature increases incubation period (Tropea et al. 2015).

Egg development duration and color : Each stage of embryonic development also showed variations in time duration and egg clutch color (Fig. 2). The color of the egg clutch changed through translucent (unfertile stage), light green (cleavage stage), deep green (blastula stage), olive green (gastrula and prenauplius stage) and tawny (post-nauplius and complete embryo stage). At the time of development, the color change from light green to tawny as the absorption of yolk and outline of the egg becomes visible (Dinakaran et al., 2013). Gregati et al. (2010) classified the egg developmental stages based on color change. However, egg observation via color changes is not practical to be applied for all species. For example, recognizing the appearance of eggs on the first day of development of adult fire shrimp, $L$. debelius is extremely challenging because of bold pigmentation throughout the body (Palmtag and Holt, 2001). In some species such as Stenopus hispidus, the transparent carapace allows direct observation of the egg by color changes, therefore, easing broodstock management at the captivity and reducing handling stress (Gregati et al., 2010).

Description of the egg development stages : In this study, seven distinguished stages of $L$. ambonensis embryonic development observed are as follows (Fig. 3 and Fig. 4).

Unfertilized stage : The egg was prolate spheroid in shape. For freshly laid egg, the yolk was initially opaque, filled with a granular yolk mass. Under the microscope, a thin transparent vitelline membrane enveloping the egg was seen. This stage was critical since any disturbance to the shrimp could lead to the removal of eggs from the pleopods.

Cleavage stage : The prolific egg was surrounded with a thin fertilization membrane that enclosed minute and uniform size of yolk mass granules. The first cleavage began by the appearance of shallow cleavage furrow on the surface of the egg. It girdled the egg along its middle region and continued to deepen and lastly cleaved the egg into two particular and equivalent blastomeres. The second cleavage process subsequently divided the yolk mass into four equal blastomeres. At this stage, the blastomeres touched the fertilization membrane at many points. All of them had identical sizes; however, after the formation of 16 blastomeres, the divisions demonstrated a tendency to become irregular. The number of blastomeres increased with repetition of cell divisions.

Blastula stage : Cell division proceeded with no apparent morphological changes in the egg until full division or blastulation was accomplished. Cleaved blastomeres were highly compact and heavily merged forming deeply irregular cells like a solid ball of aggregate cells.

Gastrula stage : Gastrulation occured after cleavage and blastula arrangement. There was a small invagination combined 

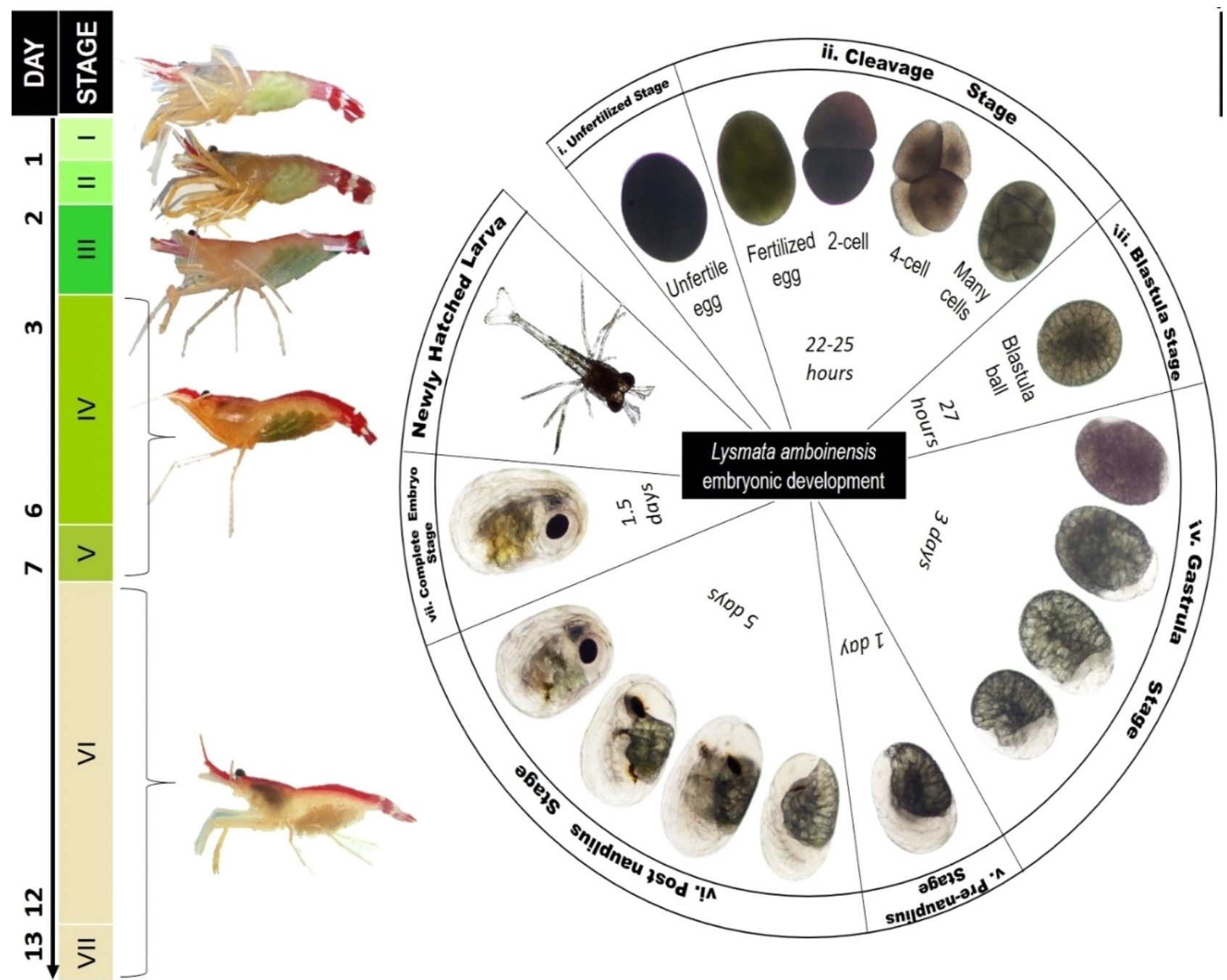

Fig. 2 : The scheme shows the color modification of berried broodstock and the cycle duration of embryonic development via different stages along 13 days of egg incubation under laboratory conditions based on the observation of four mating pairs during 60 days. Illustrations are not to scale.

with cell immigration. As migration was going on the blastodermic thickening, the surface became more conspicuous. As more and more cells composing the band sank into the yolk, it widened out and became shallow. During the process of continuous cell migration, it expanded the transparent area. Gastrulation was followed by organogenesis, where newly germ layers were formed to build individual organs in the transparent area.

Pre-nauplius stage : The position of caudal furrow was clearly marked although its form was still unclear.

Post nauplius stage : At the beginning of this stage, the optic rudiments lied flat on the surface of the yolk. The heart was visible and started to pulse irregularly. The caudal papilla was much clearer and disclosed completely. Next, the telson was noticeable. The heart beat started to regulate at the rate of 40-50 times per minute. Caudal papilla increased in length and folded. At day 9 , the average heart rate increased to 120 times per minute. The tip of the telson bent around the eye. Towards the end of this stage, the large and bright compound eyes were developed. The average heart beat increased to 180 times per minute. A continuous contraction of embryo and yolk could be seen. All appendages were long and overlapping.

Complete embryo stage : This is an advanced stage in embryonic development. The succeeding appendages such as first, second and third maxillipeds were more defined than in the earlier period. However, they could not be distinguished in the living embryo inside the envelope, since they were hidden by those in front. The movement of appendages could be seen. The average heart rate increased to 200 times per minute. The yolk reduced in quantity. The tip of the telson bent around the eye and points upwards reached almost the dorsal side. The yolk in contact with this layer broke down into a clear fluid in which vacuoles appeared. The colour was brownish-yellow and translucent. The compound eyes had become larger and lied at 

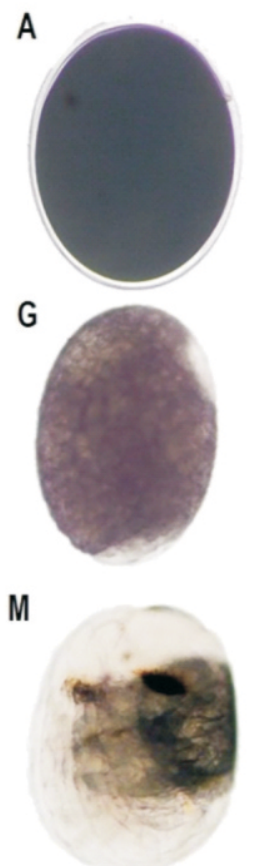

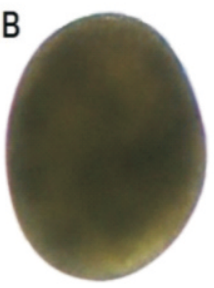

$\mathrm{H}$

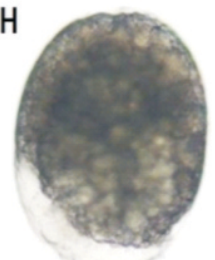

$\mathrm{N}$

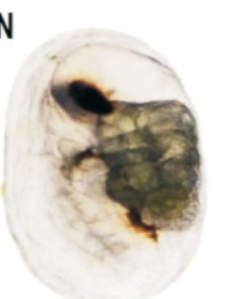

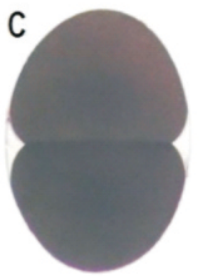

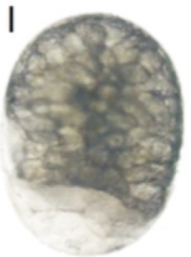

0

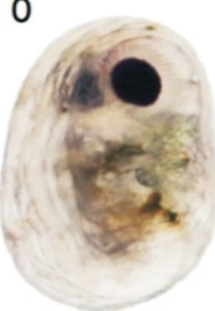

D
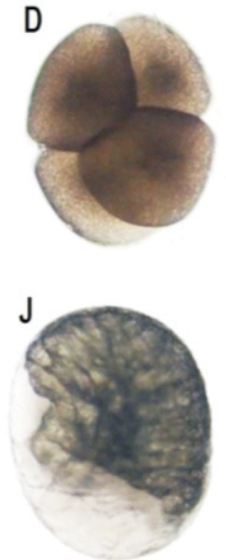

P

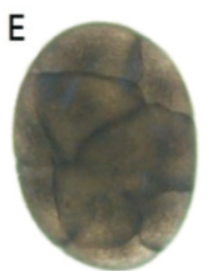

$\mathrm{K}$

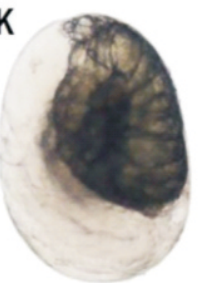

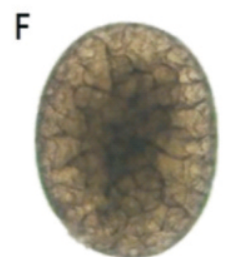

$\mathrm{L}$

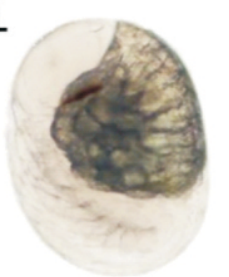

Fig. 3 : Embryonic development of L. amboinensis. (A) unfertilized stage; (B-E) cleavage stage; (F) blastula stage; (G-J) gastrula stage; (K) pre-nauplius stage; (L-O) post nauplius stage; (P) complete embryo stage. Scale bars: (A-P) $200 \mu \mathrm{m}$.
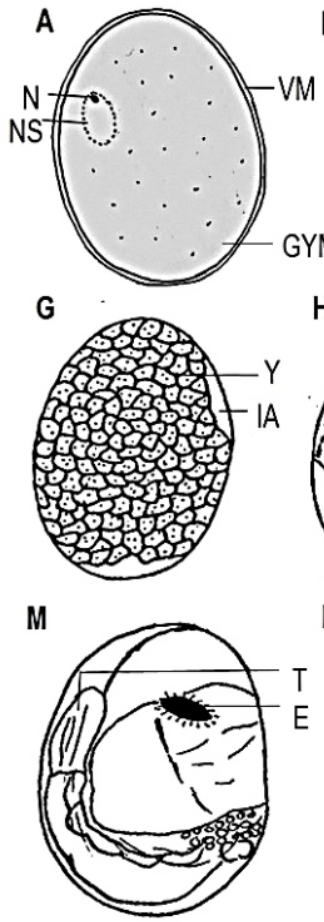

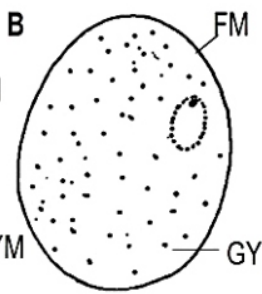

$\mathrm{H}$

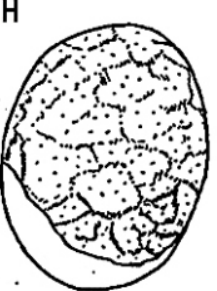

$\mathrm{N}$

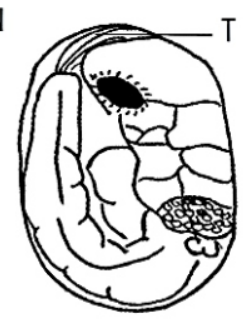

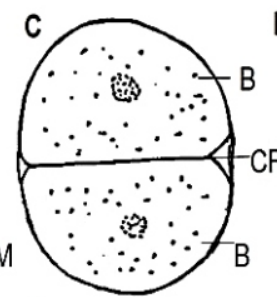
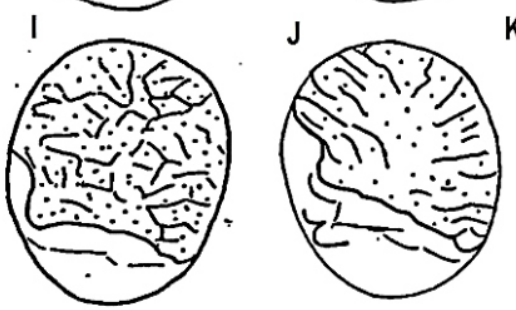

$\mathrm{K}$
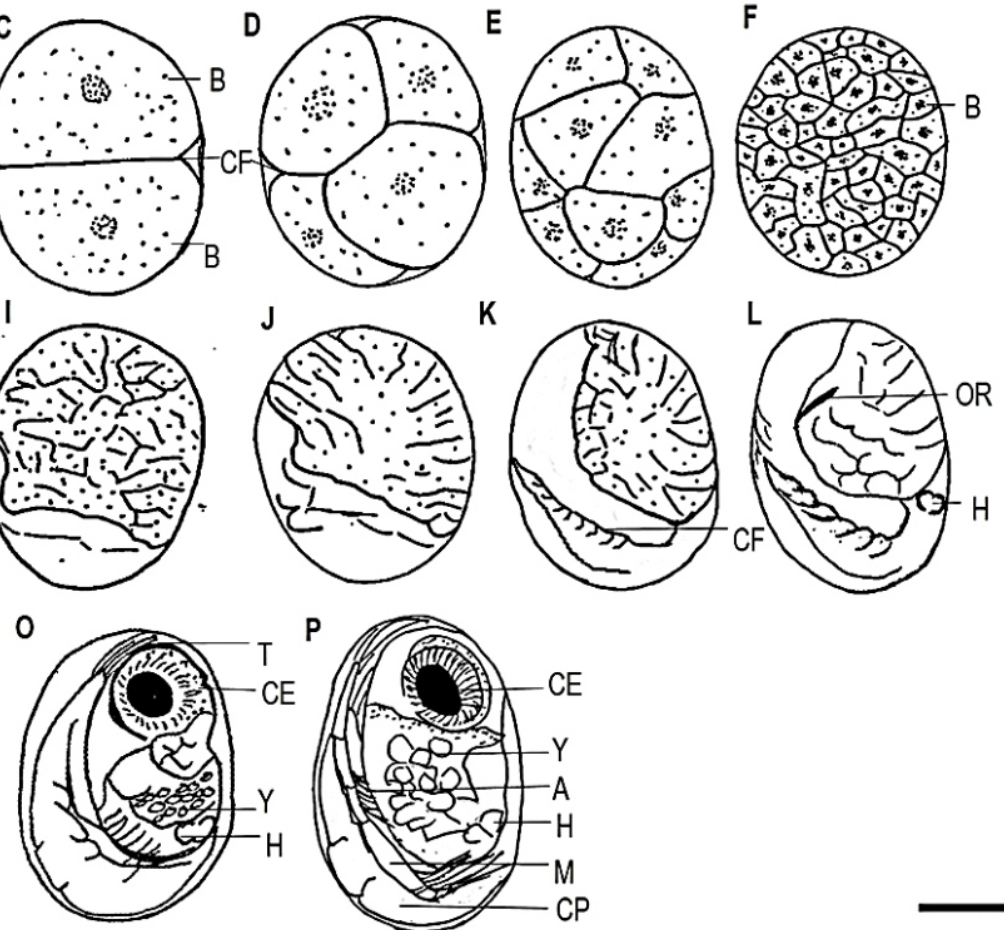

Fig. 4 : Illustration of L. amboinensis embryonic development. (A) unfertilized stage; (B-E) cleavage stage; (F) blastula stage; (G-J) gastrula stage; (K) pre-nauplius stage; (L-O) post nauplius stage; $(\mathrm{P})$ complete embryo stage. Abbreviations: A: antennule; $\mathrm{CE}$ : compound eye; CF: caudal furrow; OR: optic rudiment; E: eye; FM: fertilization membrane; B: blastomere; CF: caudal furrow; GYM: granular yolk mass; N: nucleolus; H: heart; IA: invaginate area; M: maxilliped; CP: caudal papilla; NS: nucleus; T: telson; VM: vitelline membrane; Y: yolk. Scale bars: (A-P) $200 \mu$ m. 


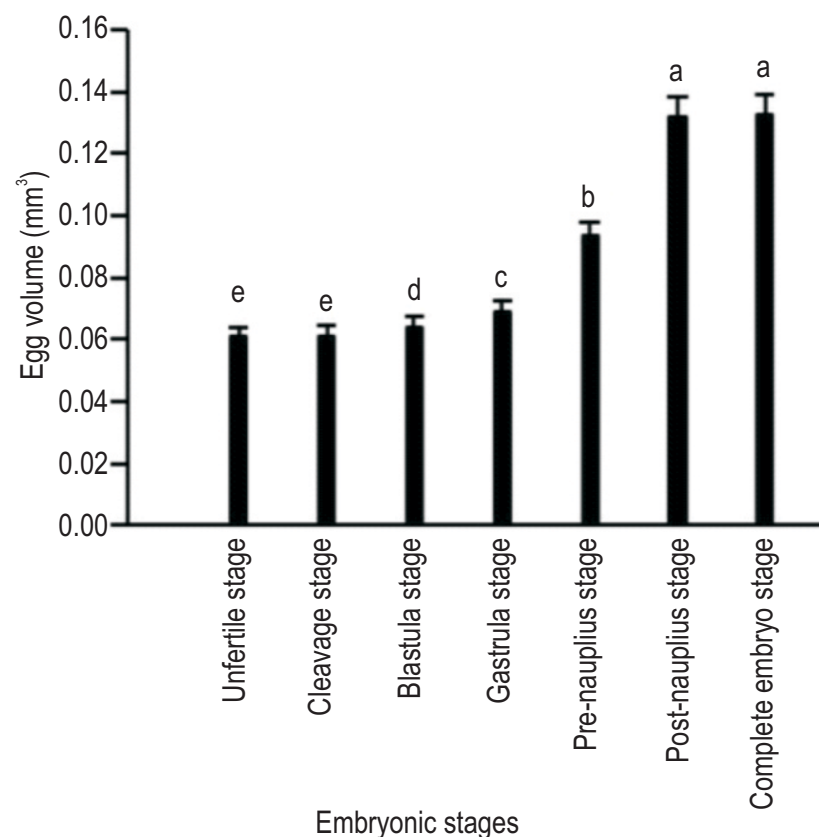

Fig. 5 : Egg volume of different embryonic stages of $L$. ambonensis. Bars are \pm S.E. $(n=30)$. Different small letters at the top of the columns indicate significantly different $(p<0.05)$. the anterior end. The eye structure clearly separated into two parts, lighter and transparent in the outer zone, while the optic lobes appeared to be more complex and darker in the internal zone. The embryonic development was complete for hatching.

In several studies the eggs stage of crustacean have been divided on the presence of distinct morphological features such as eye, heartbeat and main appendages formation (Muller et al., 2003; Sarker et al., 2012; Tracey et al., 2013; RomeroCarvajal et al., 2018; Liu et al., 2020). However, such morphological characters only start to appear in the middle of embryonic development (Dinakaran et al., 2013). Similar visible development pattern was observed in this study is in line with other researchers, where the optic rudiment spots appeared first followed by the outlines of caudal papilla and organization of main appendages (García-Guerrero and Hendrickx, 2005; GarcíaGuerrero and Hendrickx, 2006; Cuvin-Aralar, 2014).

Egg volume : Measuring the egg volume at different embryonic stages showed a significant increase $(p<0.05)$ during the embryonic development (Fig. 5). The increase in egg volume was observed as the eggs progressed during the incubation period in this study. Egg volume increased significantly during egg

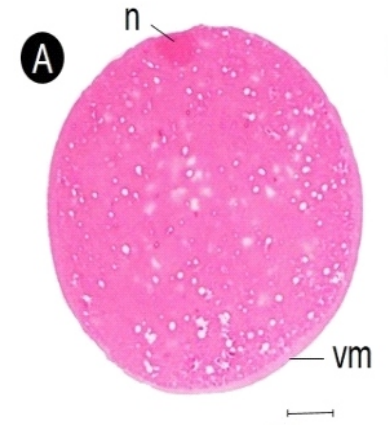

$\widetilde{50 \mu \mathrm{m}}$

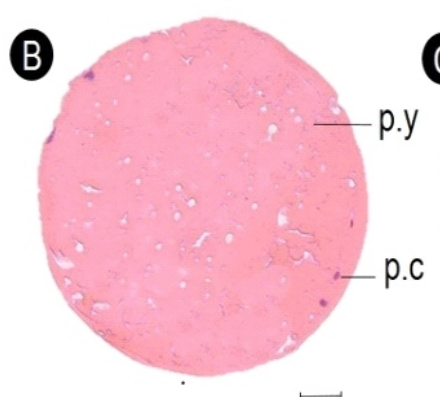

$50 \mu \mathrm{m}$
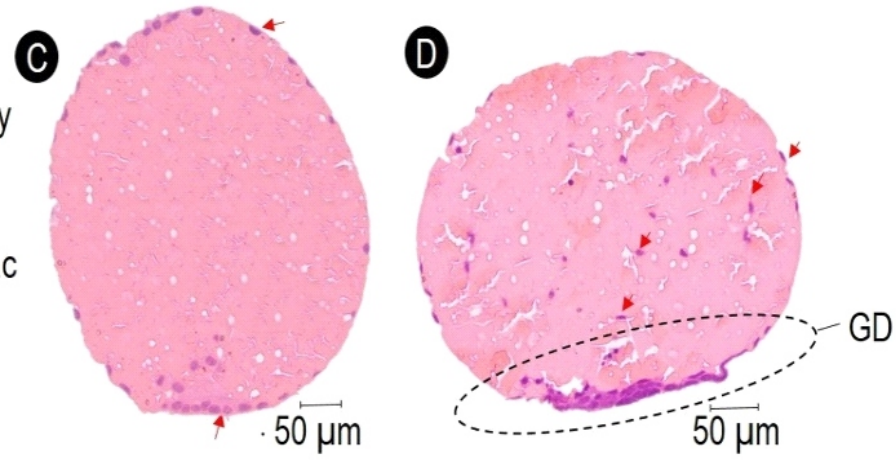

E

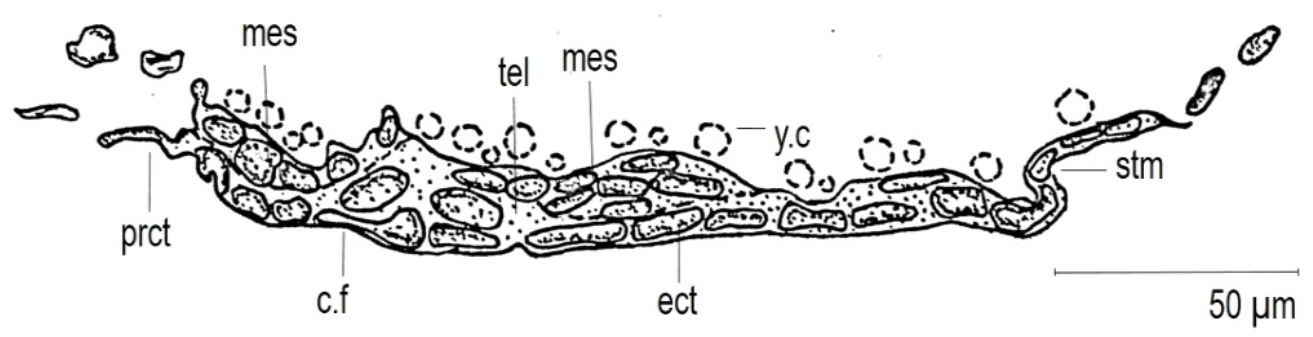

Fig. 6 : Gastrulation and establishment of germ disc. Red arrows show cluster of primordial cells begins to migrate and form germ disc in ventrolateral position prove that they are in active division. (A) Histological section of unfertile stage; (B) Histological section of late cleavage stage; (C) Histological section of late blastula; (D) Histological section of early gastrula stage, early germ disc formation and $(E)$ Illustration of germ disc formation. Abbreviations: c.f: caudal furrow; ect: ectoderm; mes: mesoderm; n: nucleus; GD: germ disc; p.c: primordial cell; prct: proctodaeum; p.y: primary yolk; stm: stomodaeum; tel: teloblastic area; vm: vitelline membrane; y.c: yolk cell. 

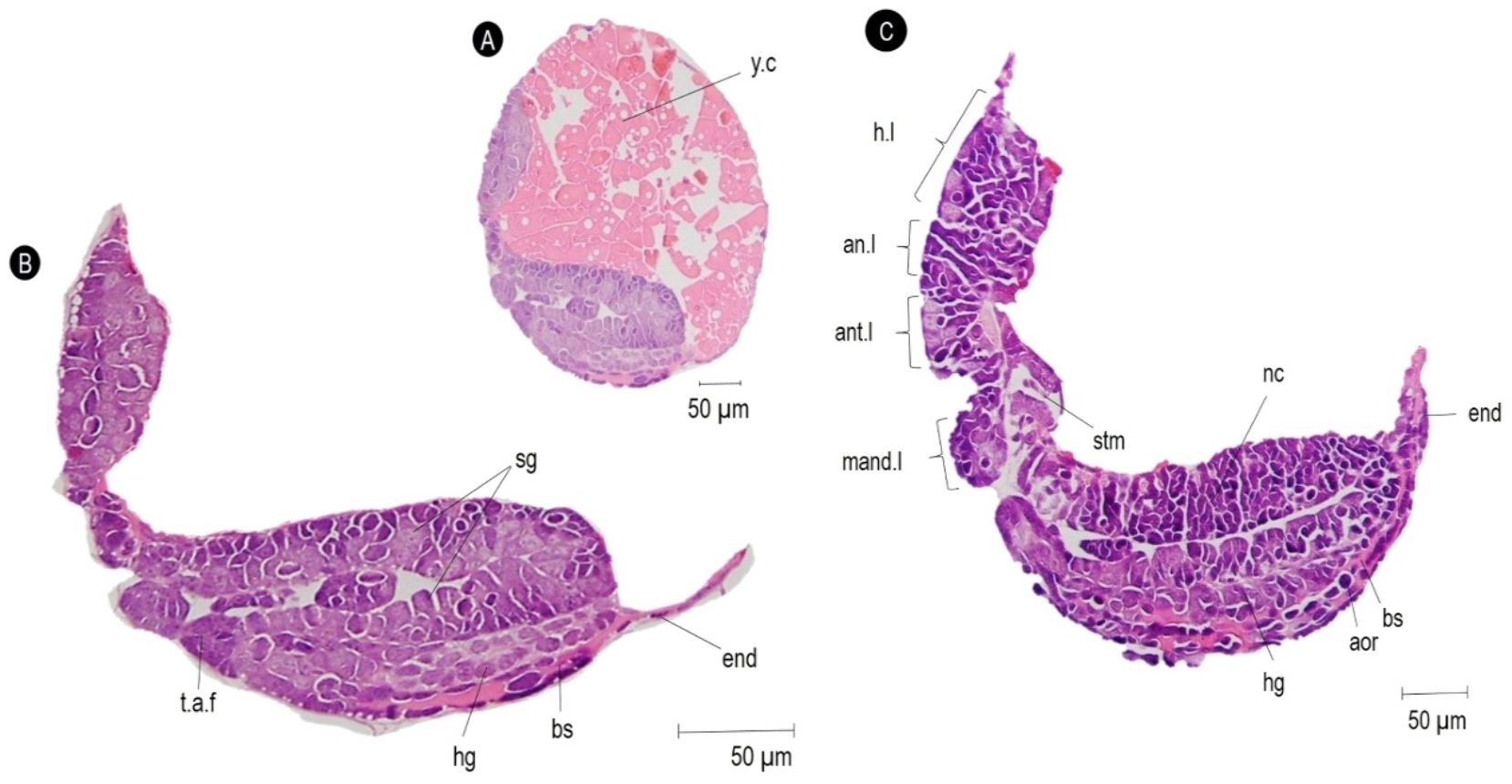

Fig. 7 : Serial cross section through embryo of $L$. amboinensis at gastrula stage. (A) Cross section of whole egg at late gastrula stage; (B) Section through the same egg, showing the organ lobe anlage; (C) Section through the same egg at a slightly later stage. Abbreviations: aor: aorta; bs: blood space; an.l: antennule lobe; ant.l: antenna lobe; end: endoderm; hg: hindgut; h.l: head lobe; mand.l: mandible lobe; nc: neural cord; sg: segmental ganglia; stm: stomodaeum; t.a.f: thoracic abdominal fold; y.c: yolk cell.

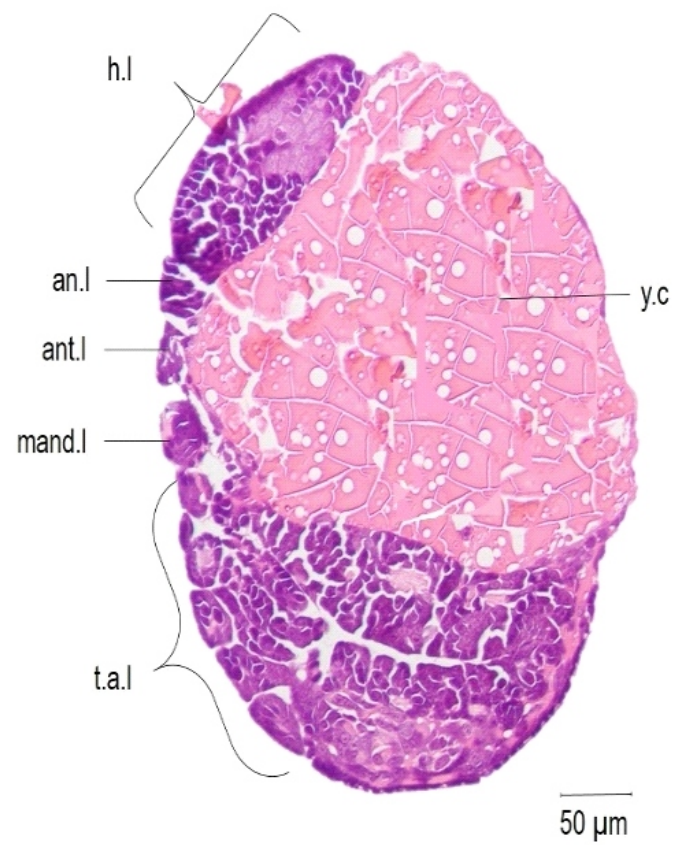

Fig. 8 : Cross section through embryo of L. amboinensis at pre-nauplius stage. Abbreviations: an.l: antennule lobe; ant.l: antenna lobe; h.l: head lobe; mand.l: mandible lobe; t.a.l: thoracic abdominal lobe; y.c: yolk cell. development from stage II to stage $\mathrm{VI}(p<0.05)$. The increment of egg volume during embryonic development is a regular feature among decapod crustaceans (Nazari et al., 2003; Zhao et al., 2007). The volume increase in the developing egg may be due to water osmotic uptake (Fukuda et al., 2016). Changes in the egg size throughout the development is important as osmotic swelling facilitates the outer membrane rupture for hatching process (Soundarapandian, 2008).

Gastrulation, establishment of germ disc and organogenesis based on histological studies : Histological study remarked features of different structures compared with direct observation of a living embryo. Several series of embryo sections were obtained. Since the entire egg was rich with yolk proportion and other cellular materials, the difficulty of sectioning was higher. The difficulty was overcome by selecting many eggs at the same stage and sectioning them together to get accurate information about their structures. As the structural details are now very prodigious, interpreting the observed parts in a single section often seem impossible. Therefore, the organ and related structures in the embryo were compared using different plane sections.

Fig. 6A shows the longitudinal sections of unfertilized egg of $L$. amboinensis. Vitelline membrane enveloping the egg 


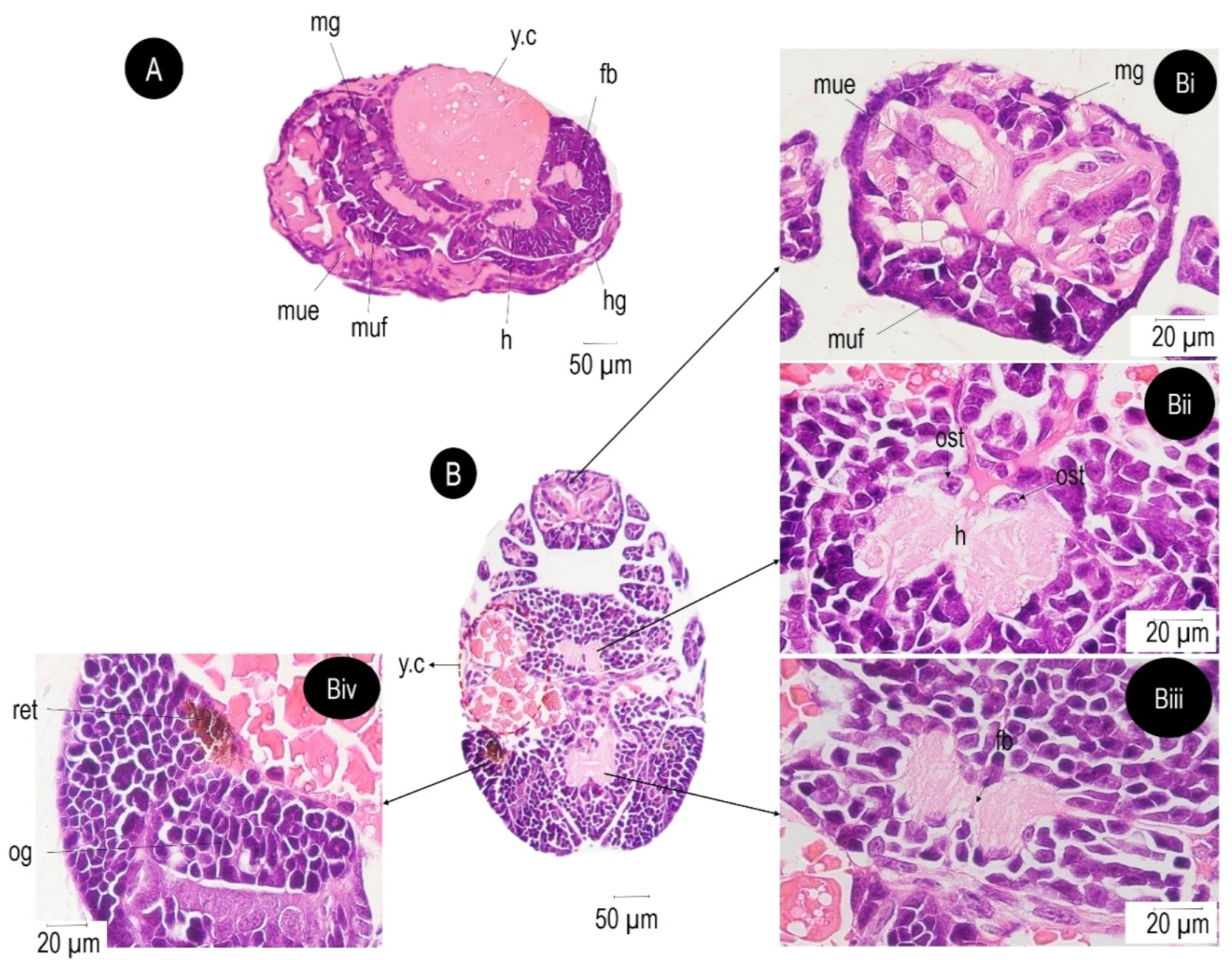

Fig. 9 : Serial cross section through embryo of $L$. amboinensis at post-nauplius stage. (A) Median tangential section of post-nauplius stage; (B) Longitudinal cross section of post-nauplius stage; (Bi) Parts of sections through the region of thoracic abdominal fold; (Bii) Cross section of developing heart; (Biii) Cross section of developing brain; (Biv) Cross section of eye; first appearance. Abbreviations: fb: fiber mass of brain; h: heart; hg: hindgut; mg: midgut; mue: extensor muscle of abdomen; muf: flexor muscle of abdomen; og: optic ganglion; ret:retina; $y . c$ : yolk cell; ost: ostium.

was clearly visible if compared to the living egg, where it was hardly distinguishable and could only be seen using microscope against a strong beam of light. The presence of numerous and small primordial cells were observed on the egg surface. Some of these cells migrated to ventro-lateral position and organized into a cell layer, proved that they were in an active division state (Fig. 6B-C). All the primordial cells descendants started to migrate together towards the initial gastrulation centre, consequently, formed a compact germ disc (Fig. 6D). Fig. 6E shows illustration of germ disc area from the developing embryo at early gastrula stage. The position of proctodaeum and caudal furrow could be recognized. It is important to note that the row of mesodermal teloblast was very much smaller than ectodermal teloblast, which was formed much earlier.
Fig. 7 represents the consecutive longitudinal sections of late gastrula. The morphology of germ disc at this stage was progressively different from the early stage. Segmentation and organogenesis were observed. The germ disc cluster was differentiated and separated by slits. Some organ lobe anlage such as head, antenna, antennule and mandible started developing and recognized in 7 days (Fig. 7B-C).

Fig. 8 shows the longitudinal sections of pre-nauplius stage. The thoracic abdominal fold or caudal papilla was formed. Some organ anlage such as heart and thoracic appendages started developing during this stage but were still incomplete.

Fig. 9A shows the median tangential section of postnauplius stage. Hindgut and mid gut could be distinguished. The prominent muscles were developed in abdomen part at this stage 

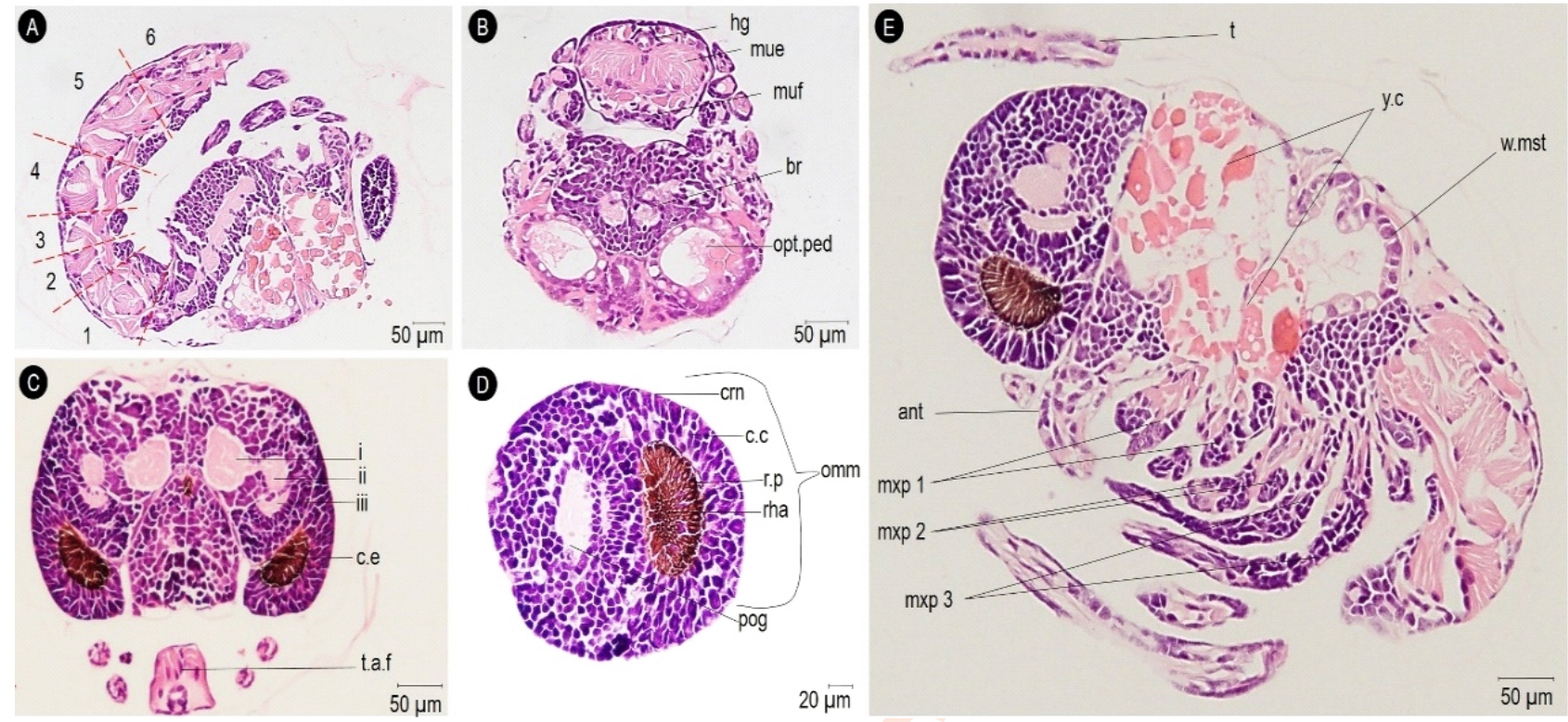

Fig. 10 : Serial cross section through embryo of $\mathrm{L}$. amboinensis which is nearly ready to hatch. (A) Median longitudinal section showed six segmentation (1-6) of abdomen muscle. (B-C) Serial transverse section of embryo at the same stage. (D) Part of sagittal section of compound eye. (E) Nearly median longitudinal section through a similar embryo. Abbreviations: ant: antenna; br: brain; c.c: crystalline cones; c.e: compound eye; crn: cornea; hg: hindgut; mue: extensor muscle of abdomen; muf: flexor muscle of abdomen; mxp1: first maxilliped; mxp2: second maxilliped; mxp3: third maxilliped; omm: ommatidie; opt.ped: optic peduncle; pog: proximal segments of optic ganglion; r.p: retinal pigments; rha: rhabdomes; t.a.f: thoracic abdominal fold; t: telson; w.mst: wall of mesenteron; $y$.c: yolk cell; i-iii: ganglia of eye stalk.

(flexor and extensor muscles). Parts of sections through the region of thoracic abdominal fold showed that both these muscles concealed the midgut (Fig. 9Bi). The longitudinal cross section from the same stage (Fig. 9Bii) showed that the heart segmentation was almost complete with a pair of ostia (singular: ostium). Besides, the fiber mass of brain could be seen in Fig. 9Biii.

The heart was located between the yolk mass and the developing caudal papilla. At this stage, simple structure of retina first appeared with thin eye pigment (Fig. 9Biv). The eye pigment was located in the distal region of optic lobe near the optic ganglion. In this study, the development of brain, abdomen muscle, compound eyes and appendages elongated was noted at this stage. These findings coincided with Jun-jie et al. (2006).

As the embryo was closed to hatching period, the organs had become highly specialized to their function and closely resembled the larvae (Fig. 10A-E). The abdomen muscles were divided into six segments (Fig. 10A). The muscles striations also made out. At this higher degree of development, the compound eye was differentiated into cell clusters as shown in Fig. 10D. The outermost layer of eye has a portion of cuticle known as cornea. Beneath the cornea lied a crystalline cone. The crystalline cone cells was quite large and conspicuous. The lower stratum of a small pigmented cells was divided into two layers; retinal pigments and rhabdomes. Besides, the gut was bigger than that in the previous stage. The mesenteron was partially filled with remaining yolk cells. As closer to hatching, the yolk cell amount was reduced compared to the previous stage. Elongation of body and other appendages such as maxillipeds were noted.

In the present study, the whole egg was homogeneously distributed with primary yolk cell in the fertilized egg stage. During the pre-nauplius stage, the thoracic abdominal fold, heart, and thoracic appendages could be observed and the yolk cell near organ anlages was greatly different from those observed at the fertilized egg stage. Cellular differentiation in the embryonic development required vast energy expenditure (Dinakaran et al., 2013). Throughout the last stage, the yolk was hydrolyzed at a high rate and embryological organs were nearly developed, leading to the establishment of physiological functions and the heart began to pulse consistently (Habashy et al., 2012). Some yolk cell in the egg still reserved until hatched. Yao et al. (2006) mentioned the remaining yolk needed as energy resources while finding the external feeding to ensure the first successful molt.

The internal embryology description of $L$. amboinensis using histological techniques provides additional or more detailed information on the development of internal organs. It is also useful for future ontogeny studies. Garcia-Guerrero et al. (2003) elucidated that the internal events were closely correlated with external ontogeny. This information provided a better understanding of the changes of metabolic pathways such as 
establishment of germ disc followed with organogenesis, which connecting interconversion of already stored substrates within the closed system of egg development. The description of reproduction cycle and embryonic development is also important for the ornamental industry as it contributes to better knowledge of this species.

\section{Acknowledgments}

This study was funded by an internal grant from Universiti Putra Malaysia (UPM); project no GP-IPB/2014/9440403. We thank the staff at the International Institute of Aquaculture and Aquatic Sciences (I-AQUAS), Universiti Putra Malaysia for their assistance during the conduct of this experiment.

\section{References}

Bauer, R.T.: Remarkable shrimp: Adaptations and natural history of the carideans. University of Oklahoma Press, Oklahoma, USA(2004).

Brillon, S., Y. Lambert and J. Dodson: Egg survival, embryonic development, and larval characteristics of northern shrimp (Pandalus borealis) females subject to different temperature and feeding conditions. Mar. Biol., 147, 895-911 (2005).

Calado, R., I. Olivotto, P.O. Miquel and G.J. Holt: Marine Ornamental Species Aquaculture. John Wiley and Sons Ltd., United Kingdom (2017).

Calado, R., L. Narciso, R. Araujo and J. Lin: Overview of marine ornamental shrimp aquaculture. In: Marine ornamental species: collection, culture \& conservation (Eds.: J.C. Cato and C.L. Brown). lowa State Press, pp. 221-230 (2003).

Calado, R., T. Pimentel, A. Vitorino, G. Dionísio and M.T. Dinis: Technical improvements of a rearing system for the culture of decapod crustacean larvae, with emphasis on marine ornamental species. Aquaculture, 285, 264-269 (2008).

Calado, R.: Marine Ornamental Shrimp. Biology, Aquaculture and Conservation. Wiley-Blackwell, U. K. (2008).

Cuvin-Aralar, M.L.A.: Embryonic development of the Caridean prawn Macrobrachium mammillodactylus (Crustacea: Decapoda: Palaemonidae). Invertebr. Reprod. Dev., 58, 306-313 (2014).

Dinakaran, G.K., P. Soundarapandian and D. Varadharajan: Embryonic development of the palaemonid prawn Macrobrachium idella idella (Hilgendorf, 1898). Cell Dev. Biol., 2, 1-6 (2013).

Fiedler, G.C.: Functional, simultaneous hermaphroditism in femalephase Lysmata amboinensis (Decapoda: Caridea: Hippolytidae). Pac. Sci., 52, 161-169 (1998).

Fukuda, B., G. Bertini and L.C.D.D. Almeida: Effect of salinity on the embryonic development of Macrobrachium acanthurus (Decapoda: Palaemonidae). Invertebr. Repr. Dev., 61, 1-8 (2016).

García-Guerrero, M., M.E. Hendrickx and H. Villarreal: Description of the embryonic development of Cherax quadricarinatus (Von Martens, 1868) ( Decapoda, Parastacidae), based on the staging method. Crustaceana, 76, 269-280 (2003).

García-Guerrero, M.U. and M.E. Hendrickx: Embryology of decapod crustaceans, II: gross embryonic development of Petrolisthes robsonae (Glassell, 1945) and Petrolisthes armatus (Gibbes, 1850) (Decapoda, Anomura, Porcellanidae). Crustaceana, $\mathbf{7 8 ,}$ 1089-1097 (2005).

García-Guerrerol, M.M. and M.E. Hendrickx: Embryology of decapod crustaceans III: embryonic development of Eurypanopeus canalensis Abele \& Kim, 1989, and Panopeus chilensis H. Milne Edwards and Lucas, 1844 (Decapoda, Brachyura, Panopeidae). Belg. J. Zool., 136, 249-253 (2006).

Gregati, R.A., V. Fransozo, L.S. López-Greco and M.L. NegreirosFransozo: Reproductive cycle and ovarian development of the marine ornamental shrimp Stenopus hispidus in captivity, Aquaculture, 306, 185-190 (2010).

Habashy, M.M., K.M. Sharshar and M.M.S. Hassan: Morphological and histological studies on the embryonic development of the freshwater prawn, Macrobrachium rosenbergii (Crustacea, Decapoda). J. Basic Appl. Zool., 65, 157-165 (2012).

Jun-jie, Y., Z. Yun-long, W. Qun, Z. Zhong-liang, H. Xian-cheng, D. Xiaowei and $A$. Chuan-guang: Biochemical compositions and digestive enzyme activities during the embryonic development of prawn, Macrobrachium rosenbergii. Aquaculture, 253, 573-582 (2006).

Leal, M.C., R.J.M. Rocha, R. Rosa and R. Calado: Aquaculture of marine non-food organisms: What, why and how?. Rev. Aquacult., 10, 1-24 (2016)

Lin, J., D. Zhang and A. Rhyne: Broodstock and larval nutrition of marine ornamental shrimp. In: Avances em nutrición acuícola vi. memorias del vi simposium internacional de nutrición acuícola (Eds.: L.E. Cruz-Suaréz, D. Ricque-Marie, M. Tapia-Salazar, M.G. Graxiola-Cortés and N. Simoes). Universidad Autónoma de Nuevo León, Cancun, pp. 277-280 (2002).

Liu, B., B. Liu, Q. Zhou, C. Sun, C. Song, Z. Huimin, Z. Yang and F. Shan: Patterns of bacterial community composition and diversity following the embryonic development stages of Macrobrachium rosenbergii. Aquacult. Rep., 17, 1-11 (2020).

Muller, Y. M. R., E. M. Nazari and M. S. Simoes-Costa: Embryonic stages of the freshwater prawn Macrobrachium olfersi (Decapoda, Palaemonidae). J. Crustac. Biol., 23, 869-875 (2003).

Nagao, J., H. Munehara and K. Shimazaki: Embryonic development of the hair crab Erimacrus isenbeckii. J. Crustac. Biol., 19, 77-83 (1999).

Nazari, E.M., M.S. Simões-Costa, Y.M.R. Müller, D. Ammar and M. Dias: Comparisons of fecundity, egg size, and egg mass volume of the freshwater prawns Macrobrachium potiuna and Macrobrachium olfersi (Decapoda, Palaemonidae). J. Crustac. Biol., 23, 862-868 (2003).

Palmtag, M.R. and G.J. Holt: Captive rearing of fire shrimp (Lysmata debelius). Texas Sea Grant College Program Research Report, pp. 1-4 (2001).

Romero-Carvajal, A., M.W. Turnbull and J.A. Baeza: Embryonic development in the peppermint shrimp, Lysmata boggessi (Caridea: Lysmatidae). Biol. Bull. 234, 000-000 (2018).

Rhyne, A.L., M.F. Tlusty, J.T. Szczebak and R.J. Holmberg: Expanding our understanding of the trade in marine aquarium animals. Peer J., 5, e2949 (2017).

Sarker, M.M, M.S. Islam and T. Uehara: Embryonic development of the estuarine crab Neosarmatium indicum (Crustacea: Brachyura: Sesarmidae) from the mangroves of the Okinawa Island, Japan. Univ. J. Zool. Rajshahi Univ., 31, 49-54 (2012).

Soundarapandian, P.: Breeding behavior and effect of salinity and osmolarity on incubation and hatching of Macrobrachium malcolmsonii (H. Milne Edwards) under laboratory conditions. Int. J. Zool. Res., 4, 81-84 (2008).

Thiel, M.: Extended parental care behaviour in crustaceans: A comparative overview. Crustaceans /ssues, 12, 211-226 (2000). 
Tracey, E., A. Pereira, M. Hughes and C. A. Korey: The embryonic development of the snapping shrimp, Alpheus angulosus mcclure, 2002 (Decapoda, Caridea). Crustaceana, 86, 1367-1381 (2013).

Tropea, C., L. Stumpf and L.S. López-Greco: Effect of temperature on biochemical composition, growth and reproduction of the ornamental red cherry shrimp Neocaridina heteropoda heteropoda (Decapoda, Caridea). PLOS ONE, 10, 1-14 (2015).

Tziouveli, V. and G. Smith: Sexual maturity and environmental sex determination in the white-striped cleaner shrimp Lysmata amboinensis. Invertebr. Reprod. Dev., 53, 155-163 (2009).

Wabnitz, C., M. Taylor, E. Green and T. Razak: From ocean to aquarium. UNEP-WCMC, Cambridge, UK (2003).
Yao, J., Y.L. Zhao, Q. Wang, Z.L. Zhou, X.C. Hu, X.W. Duan and G. AnChuan: Biochemical compositions and digestive enzyme activities during the embryonic development of prawn, M. rosenbergii. Aquaculture, 253, 573-582 (2006).

Zhang, D., J. Lin and R.L. Creswell: Mating behavior and spawning of the banded coral shrimp Stenopus hispidus in the laboratory. $\mathrm{J}$. Crustac. Biol., 18, 511-518(1998).

Zhao, Y., Y. Zhao and C. Zeng: Morphogenesis and variations in biochemical composition of the eggs of Macrobrachium nipponense (de Haan, 1849) (Decapoda, Caridea, Palaemonidae) during embryonic development. Crustaceana, 80, 1057-1070 (2007). 